\title{
Alternate migration strategies of eastern monarch butterflies revealed by stable isotopes
}

https://doi.org/10.1515/ami-2018-0006

Received June 8, 2018; accepted October 30, 2018

\begin{abstract}
Alternative life history strategies are mechanisms by which organisms are able to maximize fitness across a range of environmental conditions. Fitness is maximized by different strategies depending on context, resulting in trade-offs between life history strategies. Monarch butterflies (Danaus plexippus) employ both migratory and resident life history strategies. Since residents breed throughout the year, but migrants overwinter in reproductive diapause, there are fitness trade-offs between the two strategies. We used stable isotope analysis to evaluate the geographic origins of monarchs in a yearround population in south Florida. Based on stable isotope profiles of hydrogen and carbon $\left(\delta^{2} \mathrm{H}\right.$ and $\delta^{13} \mathrm{C}$ values), we found that $48 \%(16 / 33)$ of monarchs collected in south Florida are migrants that originated from outside the sampling region. Migrants had a larger wing length than residents; thus, switching to a resident strategy could alter their probability of reproductive success. Further work is needed to investigate the mechanism underlying this pattern, but these findings show that alternate life history strategies and sex-specific behaviors are underexplored factors influencing monarch migration and evolution.
\end{abstract}

Keywords: Danaus plexippus, connectivity, alternative strategies, hydrogen stable isotopes, carbon stable isotopes

\footnotetext{
*Corresponding author: Hannah B. Vander Zanden , University of Florida, Gainesville, United States, E-mail: hvz@ufl.edu Carol L. Chaffee, California State University Fullerton Antonio González-Rodríguez, Universidad Nacional Autónoma de México (UNAM)

D.T. Tyler Flockhart, University of Maryland Center for Environmental Science, Appalachian Laboratory

D. Ryan Norris, University of Guelph

Marta L. Wayne, University of Florida

\#Joint first authors
}

\section{Introduction}

Alternative life history strategies are found in a wide variety of taxa, including birds [1], butterflies [2], crickets [3], frogs [4], grasshoppers [5], horseshoe crabs [6], lizards [7], and salmon [8]. In particular, populations that exhibit alternative life history strategies in migratory behavior are termed to show "partial migration," with some individuals exhibiting residency and some engaging in migration [9]. While the details between strategies vary as widely as the taxa in which they are observed, a key component in all cases is a trade-off, often between a strategy that is best under one set of conditions, and an alternate strategy that provides a fitness advantage under a different set of conditions. The relevant conditions may be environmental, physiological or a combination of both. Selection of a strategy therefore involves one or more environmental or physiological thresholds that lead to an individual following a particular strategy.

Monarch butterflies (Danaus plexippus) are a charismatic species of conservation concern that also employ two contrasting life history strategies: migratory or resident. Little is known about why individuals follow one strategy or another. Over the last two decades, the Eastern migratory monarch population at the Mexican overwintering colonies has declined by approximately $80 \%$, and recent models predict a substantial probability of quasi-extinction in the next 20 years [10]. Adults deposit eggs on many milkweed species (Asclepias spp.), the leaves of which are consumed by developing larvae. A loss of this breeding habitat has been suggested as the major cause for the population decline, as milkweed has been reduced in agricultural areas with the use of herbicides and adoption of genetically modified crops [1113], although other evidence suggests that this population may be limited by factors that occur during migration [14, 15]. In either case, characterizing the migratory strategies and geographic distribution of this species is critical to create spatially explicit demographic models for directing conservation measures $[11,16]$. 
Monarchs that follow the migratory strategy are found in the temperate zone in North America, and this migration pattern consists of several successive generations that migrate northward through the spring and summer. Butterflies in these generations usually have 6-8 week life spans, although the average life span can vary with temperature. Eastern North American monarchs that emerge in the late summer or fall, however, are in a reproductive diapause [17]. This generation delays reproduction until the following spring after they have undertaken the arduous migration southward to the overwintering grounds in central Mexico along several major routes. In the spring, these same butterflies break diapause and mate before beginning the migration north, beginning the first generation of many that continue the migration northward. The overwintering generation of monarchs thus have life spans nearly three times as long as their spring and summer counterparts.

Individuals following a resident strategy, however, neither enter diapause nor migrate, and are reproductively active throughout the year. Monarchs that follow this alternative life history strategy are found in isolated resident colonies scattered at locations across the southern United States [18-22] that are consistent with the predicted range of temperature and moisture regimes that would permit adult survival during the winter [23]. Decreasing photoperiod and lower temperature are environmental cues that trigger monarch diapause during larval development [17], and the changes in photoperiod and temperature at sub-tropical and tropical latitudes are likely insufficient to trigger diapause. Thus, monarchs born into a resident population in sub-tropical or tropical latitudes are unlikely to enter diapause and are therefore unlikely to adopt a migratory strategy. However, it is possible that some monarchs born in the main migratory population could enter resident populations, break diapause, and switch to a resident life history strategy to breed year-round [24].

Previous research indicates resident populations in south Florida occur year-round [e.g., 21, 25-28], but the degree of connectivity with the migratory population has not been examined. The use of cardenolide fingerprinting has revealed that southern Florida populations receive northern-origin migratory monarchs during the autumn that break diapause and begin breeding [21]. However, the geographic scope of the cardenolide fingerprinting method is broad, such that the possible range of migrant individuals spans Georgia to Canada [21]. Thus, the purpose of our study was to determine the geographic origin of monarchs in south Florida populations. We hypothesized that natal location would be a key determinant of life history strategy: butterflies eclosing in a resident population would follow a resident strategy, and butterflies eclosing elsewhere would follow a migratory strategy. Extrinsic factors such as weather displacement could result in conditions that would cause migrating monarchs to break diapause and start mating. However, if intrinsic factors are involved in determining migratory destination, then the trigger to switch to an alternate destination most likely occurs prior to or during migration toward the overwintering colonies. Therefore, we further hypothesized that this trigger would be condition-dependent.

Stable isotopes are commonly used as indicator of geographic origin for migratory species [29]. Organisms integrate the local isotopic signal from their diet and drinking water during the period of tissue synthesis, and inert tissues such as chitin remain unchanged when an individual migrates. The isotopic signals in adult monarch wings are assimilated during the larval stage prior to metamorphosis and therefore reflect natal origin [30]. Hydrogen isotope $\left(\delta^{2} \mathrm{H}\right)$ values in monarch wings are related to those in precipitation, and carbon $\left(\delta^{13} \mathrm{C}\right)$ isotope values reflect nutrients obtained from milkweed plants [31]. The geographic distribution of both $\delta^{2} \mathrm{H}$ and $\delta^{13} \mathrm{C}$ values is largely latitudinal. For precipitation, rainout of heavy isotopes as airmasses move northward and inland across continents results in lower $\delta^{2} \mathrm{H}$ values in more northern latitudes [32]. In milkweed, these patterns are driven by climate and water availability, with higher $\delta^{13} \mathrm{C}$ values at more northern latitudes [33]. Probabilistic assignments incorporating both elements were used to designate south Florida monarchs as migrants or residents. To investigate characteristics related to condition and potential fitness of immigrant individuals, we also examined wing size between migrants and residents. Wing-size in monarch has been previously linked to migratory status and may be influenced by sexual selection, and thus may be key component of the monarch life history strategy $[34,35]$.

\section{Methods}

\subsection{Specimen Collection}

Monarchs were collected from three sites in south Florida ( $n=33$ ) in 2011 (Table 1). Live specimens were immediately placed in glassine envelopes after capture and stored at $-20^{\circ} \mathrm{C}$ for at least 12 hours prior to measurement and dissection. Sex was determined by presence or absence of the androconium on the dorsal side of the hindwing before separating wings from bodies, and wings were returned to the glassine envelopes for later stable isotope analysis. 
Table 1. Collection site and natal origin summary for monarch butterflies collected in south Florida. See Sup. Mat. Fig. S3 for individual origin maps.

\begin{tabular}{|c|c|c|c|c|c|c|}
\hline \multirow[t]{3}{*}{ Site Name } & \multirow[t]{3}{*}{ Collection dates } & \multirow[t]{3}{*}{ Location (Lat/Long) } & \multicolumn{4}{|c|}{ \# Specimens } \\
\hline & & & \multicolumn{2}{|c|}{ Male $(n=25)$} & \multicolumn{2}{|c|}{ Female $(n=8)$} \\
\hline & & & Resident & Migrant & Resident & Migrant \\
\hline Homestead, FL & Feb - Mar 2011 & $\begin{array}{l}\text { N } 25.47 \\
\text { W } 80.44\end{array}$ & 2 & 4 & 4 & 0 \\
\hline Miami, FL & Feb - Mar 2011 & $\begin{array}{l}\text { N } 25.69 \\
\text { W } 80.29\end{array}$ & 2 & 3 & 3 & 0 \\
\hline $\begin{array}{l}\text { Naples Botanical Garden, } \\
\text { FL }\end{array}$ & Oct - Dec 2011 & $\begin{array}{l}\text { N } 26.11 \\
\text { W } 81.77\end{array}$ & 6 & 8 & 0 & 1 \\
\hline & Total & & 10 & 15 & 7 & 1 \\
\hline
\end{tabular}

Forewing size was measured as a proxy for body size. Forewing morphology is also likely to be important during soaring flight, as monarchs cover the majority of their hindwings while soaring [34]. Forewing length was measured from the white spot adjacent to the body to the point between the two white spots at the tip of the forewing (see Sup. Mat. Fig. S1 for illustration of wing landmarks). Although there were slight variations in wing patterns, these two markers were consistently used to ensure that homologous sections of the wing were measured. Measurements were recorded to the nearest millimeter.

\subsection{Stable Isotope Analysis}

One hindwing from each specimen was washed in a 2:1 chloroform:methanol solution, then air dried. Small sections of hindwing of both black and orange pigmentation [36] were cut and placed into capsules (3x5mm silver capsules for hydrogen and $5 \times 9 \mathrm{~mm}$ tin capsules for carbon) for stable isotope analysis. All results are expressed in the following conventional delta $(\delta)$ notation $\delta=$ (Rsample - Rstandard) -1 in units per mil $(\%)$ where Rsample and Rstandard are the corresponding ratios of heavy to light isotopes in the sample and international standard, respectively. International standards include Vienna Standard Mean Ocean Water (VSMOW) for ${ }^{2} \mathrm{H}$, Vienna Pee Dee Belemnite (VPDB) for ${ }^{13} \mathrm{C}$, and atmospheric $\mathrm{N}_{2}$ for ${ }^{15} \mathrm{~N}$.

Hydrogen isotope values were measured in samples weighing $0.35( \pm 0.02) \mathrm{mg}$ using the comparative equilibration process [37] at one of two labs. Homestead and Miami samples were analyzed at the Colorado Plateau Stable Isotope Laboratory at Northern Arizona University using a thermo-chemical elemental analyzer (Thermo Electron) interfaced via a CONFLO II to a Delta $\mathrm{XL}$ isotope ratio mass spectrometer (Thermo Scientific). The following keratin reference materials were used to calibrate all hydrogen results: CBS (caribou hoof standard) and KHS (kudu horn standard) with isotopic compositions of -197 and $-54.1 \%$, respectively. The standard deviation of the in-house keratin SJ reference was 1.5\%o $(n=7)$. Naples samples were analyzed at the University of Western Ontario in London, Ontario using a Uniprep-System (Eurovector) connected to a high temperature conversion elemental analyzer (Thermo Scientific) interfaced to a DeltaV isotope ratio mass spectrometer (Thermo Scientific). CBS and KHS were used to calibrate all hydrogen results. The standard deviation of the in-house keratin Spectrum 1 reference was $0.51 \%$ o $(\mathrm{n}=3)$.

Carbon isotope values were also measured at one of two labs. Homestead and Miami samples weighing 0.825 $( \pm 0.05) \mathrm{mg}$ were analyzed at the Light Stable Isotope Mass Spec Lab at the University of Florida using a Carlo Erba NA 1500 CNS elemental analyzer (Thermo Scientific) interfaced via a ConFlo II to a DeltaV Advantage isotope ratio mass spectrometer (Thermo Scientific). The reference material USGS40 (L-glutamic acid, $\delta^{13} \mathrm{C}=-26.29 \%$ ) was used to calibrate carbon results. The standard deviation of USGS40 was $0.05 \%$ o $(n=5)$. Naples samples weighing $1.0( \pm 0.1) \mathrm{mg}$ were analyzed at the University of Western Ontario in London, Ontario using a ECS 4010 elemental analyzer (Costech) interfaced to a DeltaV Plus isotope ratio mass spectrometer (Thermo Scientific). The standard deviation of USGS40 was $0.01 \%$ o $(n=2)$.

\subsection{Estimating Geographic Origin}

The residency status of the monarchs from both Florida sites was estimated with a likelihood-based approach using isotopic maps, or isoscapes, to evaluate the potential geographic origin of each individual across the spatial range evaluated. We used both amount-weighted growing season precipitation $\left(\delta^{2} \mathrm{H}_{\text {precip }}\right)$ [38] and wing-chitin $\left(\delta^{13} \mathrm{C}_{\text {monarch }}\right)$ [39] isoscapes for assignment. We rescaled 
the $\delta^{2} \mathrm{H}_{\text {precip }}$ values to those expected for monarch wing tissue using the previously published linear relationship $\left(\delta^{2} \mathrm{H}_{\text {monarch }}=0.62 \star{ }^{2} \delta^{2} \mathrm{H}_{\text {precip }}-76\right)$ [39]. The $\delta^{13} \mathrm{C}_{\text {monarch }}$ isoscape [39] was originally derived from kriging of monarch and milkweed samples (corrected to monarch tissue using a discrimination factor of $-0.5 \%$ ) from across eastern North America [31, 40], and the geographic extent of the $\delta^{13} \mathrm{C}_{\text {monarch }}$ isoscape served as the spatial range considered in the assignment to origin process. The resolution of both $\delta^{2} \mathrm{H}_{\text {monarch }}$ and $\delta^{13} \mathrm{C}_{\text {monarch }}$ isoscapes was 20' cells (Fig. 1).

For each individual, geographic assignments were made using both $\delta^{2} \mathrm{H}_{\text {monarch }}$ and $\delta^{13} \mathrm{C}_{\text {monarch }}$ values of the wing sample to estimate the likelihood that each pixel within the considered spatial domain was the natal origin with the following bivariate normal probability function:

$f\left(x, y \mid \mu_{i}, \Sigma\right)=\frac{1}{\left(2 \pi \sigma_{x} \sigma_{y} \sqrt{1-\rho^{2}}\right)} \exp \left(-\frac{1}{2\left(1-\rho^{2}\right)}\left[\frac{\left(x-\mu_{x}\right)^{2}}{\sigma_{x}^{2}}+\frac{\left(y-\mu_{y}\right)^{2}}{\sigma_{y}^{2}}\right.\right.$ $\left.\left.-\frac{2 \rho\left(x-\mu_{x}\right)\left(y-\mu_{y}\right)}{\sigma_{x} \sigma_{y}}\right]\right)$

where $f\left(x, y, \mid \mu_{i}, \Sigma\right)$ is the likelihood that an individual with $\delta^{2} \mathrm{H}_{\text {monarch }}$ value $=x$ and $\delta^{13} \mathrm{C}_{\text {monarch }}$ value $=y$ originated from cell $i$ with mean $\delta^{2} \mathrm{H}_{\text {monarch }}$ and $\delta^{13} \mathrm{C}_{\text {monarch }}$ values equal to the components in the vector $\mu_{i}$ derived from the $\delta^{2} \mathrm{H}_{\text {monarch }}$ and $\delta^{13} \mathrm{C}_{\text {monarch }}$ isoscapes. The variance-covariance matrix $\Sigma$ is decomposed on the right-hand side of the equation such that $\rho$ is the correlation between $\delta^{2} \mathrm{H}_{\text {monarch }}$ and $\delta^{13} \mathrm{C}_{\text {monarch }}$ values in chitin, which was estimated from 124 known-origin monarchs in North America [31]. The error in $\delta^{2} \mathrm{H}_{\text {monarch }}$ and $\delta^{13} \mathrm{C}_{\text {monarch }}$ values is represented by $\sigma^{2}{ }_{x}$ and $\sigma_{y}^{2}$, respectively. Two error sources were pooled using the equation:

$$
\sigma_{\text {pooled }}=\sqrt{\sigma_{\text {among }}^{2}+\sigma_{\text {iso }}^{2}}
$$

These variance estimates were calculated from the known-origin monarchs in the Hobson et al. [25] dataset such that $\sigma^{2}{ }_{\text {among }}$ represents the average variance among individuals at a site $\left(\delta^{2} \mathrm{H}_{\text {monarch }} \sigma_{\text {among }}^{2}=29.2 \%\right.$ and $\delta^{13} \mathrm{C}_{\text {monarch }}$ $\sigma_{\text {among }}^{2}=0.07 \% 0$ ) and $\sigma_{\text {krig }}^{2}$ represents the average variance in the difference between the measured values in the monarch sample and the predicted values at the collection locations on the isoscape $\left(\delta^{2} \mathrm{H}_{\text {monarch }} \sigma_{\text {iso }}^{2}=125.4 \%\right.$ and $\delta^{13} \mathrm{C}_{\text {monarch }} \sigma^{2}{ }_{\text {iso }}=0.82 \% 0$ ).

To classify individuals as residents or migrants, we used an odds ratio (OR) framework to determine the likelihood of the capture site as the natal origin. In this approach, the odds of any given cell are compared to the most probable cell. The posterior odds of each cell $P(i) /(1-P(i))$ were compared to the odds of the cell with the maximum probability $P(\max ) /(1-P(\max ))$ with the following equation:

$$
O R=\frac{\frac{P(i)}{1-P(i)}}{\frac{P(\max )}{1-P(\max )}}
$$

We used a 2:1 odds ratio threshold. If the posterior odds ratio at the capture location did not meet the 2:1
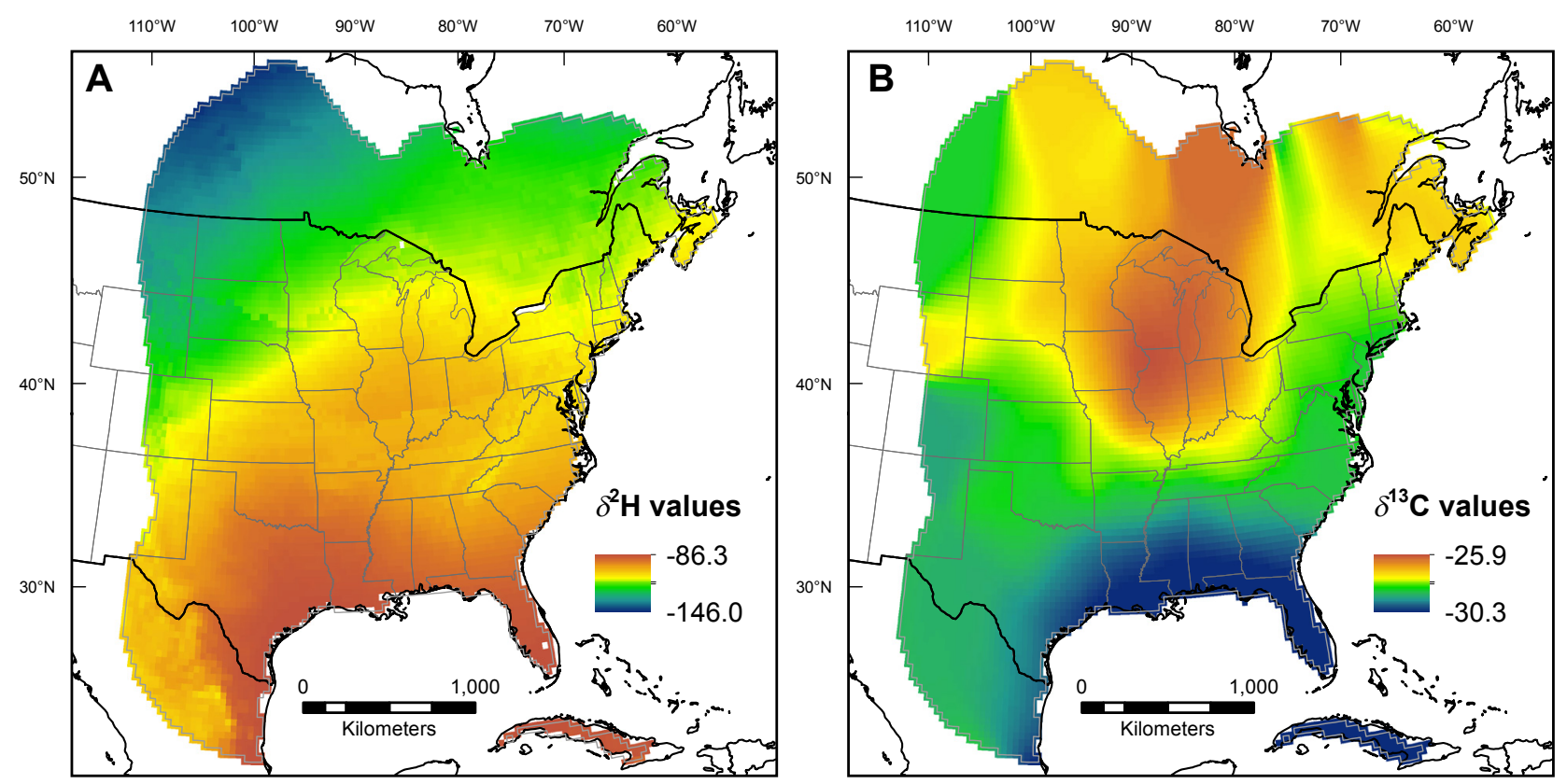

Figure 1. Derived hydrogen (a) and carbon (b) isoscapes of monarch tissue. The $\delta^{2} \mathrm{H}_{\text {monarch }}$ isoscape is based on amount-weighted growing season precipitation $\delta^{2} \mathrm{H}_{\text {precip }}$ values [32] using the rescaling equation $\left(\delta^{2} \mathrm{H}_{\text {monarch }}=0.62{ }^{*} \delta^{2} \mathrm{H}_{\text {precip }}-76\right)$ determined by Flockhart et al. [33].The $\delta^{13} C_{\text {monarch }}$ isoscape was interpolated from a combination of $\delta^{13} \mathrm{C}$ measurements from monarch wing tissue and measurements of milkweed adjusted to monarch tissue [33]. 
threshold, the individual was classified as a migrant, while a value above the threshold was classified as a resident. Migrant and resident maps were summed separately after thresholding to depict overall patterns of origin in the two groups.

\subsection{Statistical Analysis}

We tested the difference in size between resident and migrant males but not females, as only one female was determined to be a migrant. Because sample sizes were small even for the males, we conducted the analysis by randomly shuffling the residency status variable five hundred times and observing the distribution of $F$ statistics from the one-way ANOVA of each permuted dataset. The program $\mathrm{R}$ was used for all spatial and statistical analysis [41].

\section{Results}

Using the combined $\delta^{2} \mathrm{H}_{\text {monarch }}$ and $\delta^{13} \mathrm{C}_{\text {monarch }}$ values, 16 $(48 \%)$ individuals were classified as migrants and 17 (52\%) were classified as residents (Table 1, Sup. Mat. Table S1). Over half of the males (15 of 25) were migrants, while the majority of females ( 7 of 8 ) were residents (Table 1), though fewer females were sampled overall. The percentage of migratory individuals ranged from $38-60 \%$ among the three collection sites (Fig. 2). Based on natal origin, migrant monarchs that entered the south Florida population originated from throughout the North American breeding territory, with a higher density of likely

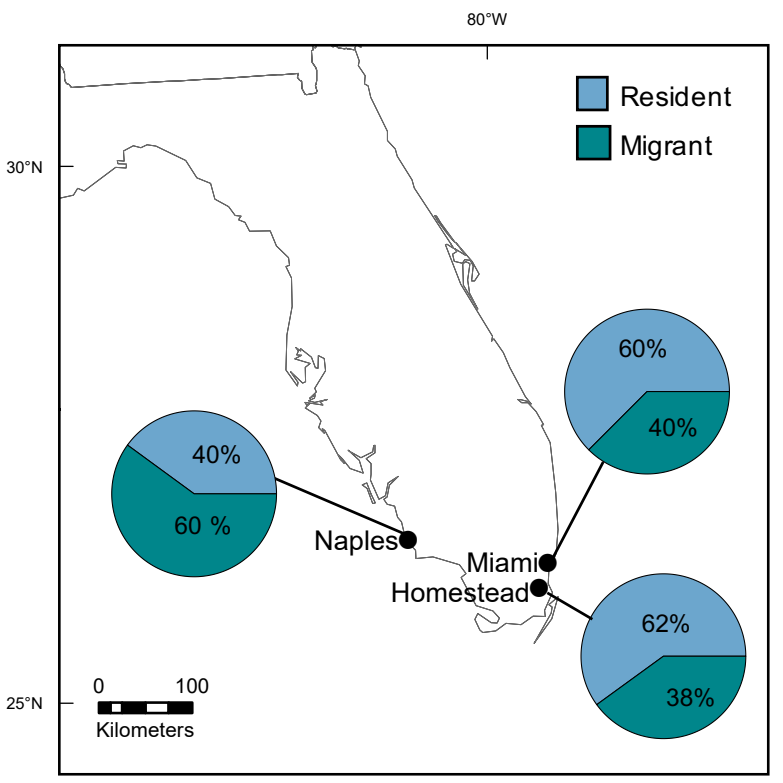

Figure 2. Map of monarch collection sites with percentage of individuals classified as migrant or resident based on $\delta^{2} \mathrm{H}$ and $\delta^{13} \mathrm{C}$ values. origin in the regions of the midwest and southwest (Fig. 3, Sup. Mat. Fig. S3). Migrant male monarchs that entered the south Florida population were larger than resident males based on wing length (Figs. 4 and S2; $P=0.024$ ).

\section{Discussion}

\subsection{Migration strategy}

Our results suggest that migratory monarchs enter the non-migratory south Florida population. Monarchs following the Atlantic flyway could end up in south Florida simply by continuing to follow the Atlantic coast, rather than heading west across Georgia or the Florida peninsula to continue along the Gulf coast. However, our stable isotope data suggest that monarchs in south Florida originated from locations throughout most of the summer range of the migratory population, rather than solely from animals expected to follow the Atlantic coast route (Fig. 2a). The summary map depicts regions with high density of individuals originating from the Midwest and near the Texas-Oklahoma border. The Midwest corresponds with the natal region that has contributed the highest proportion of individuals to the Mexican overwintering population over nearly four decades [42]. While there was low likelihood of origin from more northern areas in the breeding range, it is possible that these northern regions with lower relative contributions to the overwintering population [42] were not detected in the migrant population as a result of the small sample size. Similarly, a previous study used a combination of chemical tracer techniques to reveal an influx of migrants into resident Cuban populations over multiple years [43]. The origin of the migrant monarchs to Cuba was mostly southeastern Canada and the eastern United States, and the migrant subspecies (D. p. plexippus) was likely hybridizing with the resident subspecies (D. p. megalippe) [43].

The proportion of individuals classified as migrants in this study was $48 \%$, which was much higher than the $7 \%$ immigration rate measured at a south Florida population through cardenolide fingerprinting [21]. The percentage of migrants ranged from $38-60 \%$ among sites, and two sites measured in a previous study had significant differences in the proportions of northern migrants [21]. Collections from two of the three sites in this study occurred in February and March, which would suggest that the migrant monarchs had likely overwintered in Florida. The Naples sample collections occurred in October through December, and so we cannot be certain if they remained to 

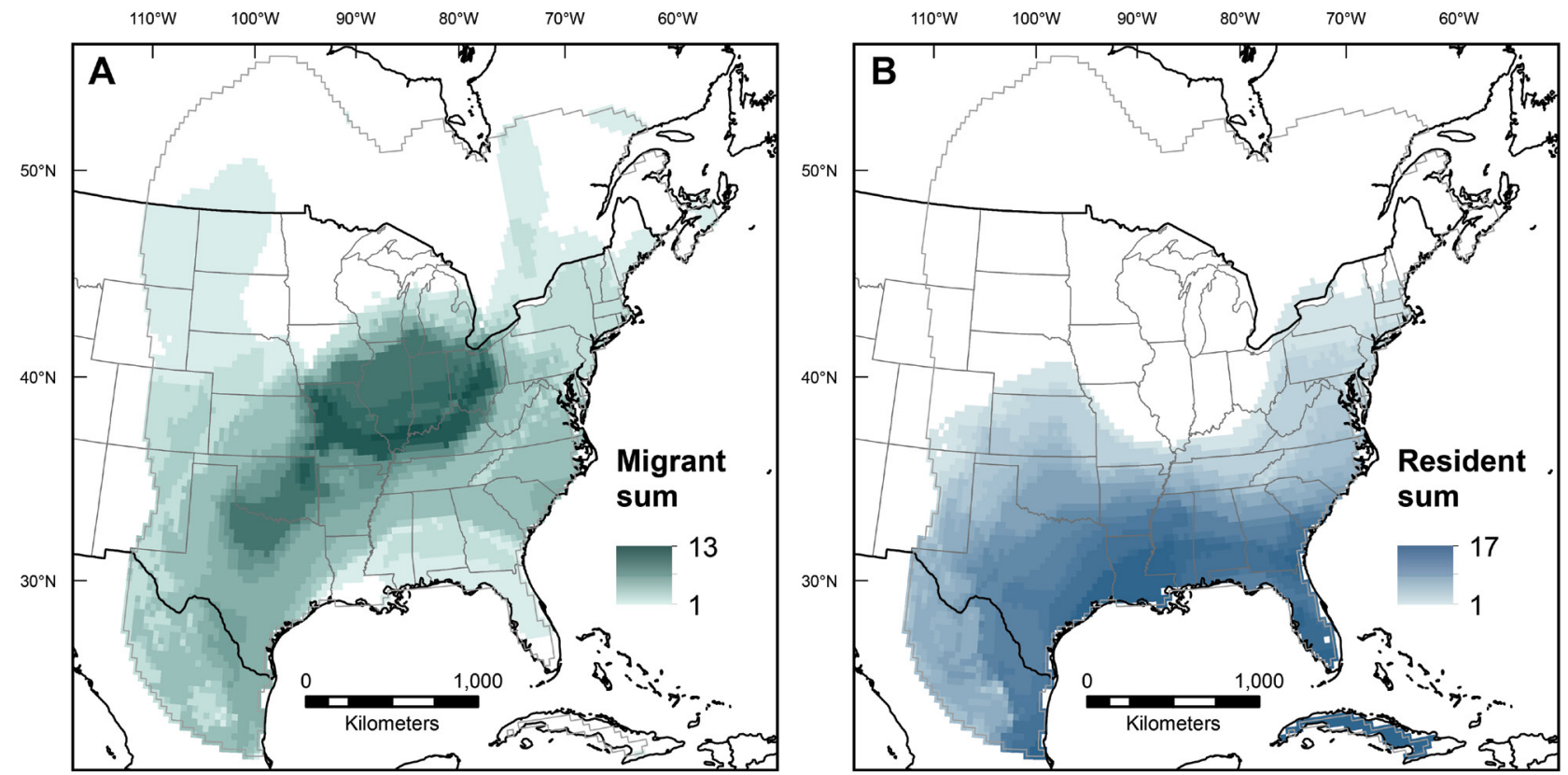

Figure 3. Summary maps of likely origin for (a) migratory $(n=16)$ and (b) resident monarchs $(n=17)$ based on geographic assignment using $\delta^{2} \mathrm{H}$ and $\delta^{13} \mathrm{C}$ values in wing tissue. Each cell depicts the sum of the number of individual monarchs for which the likely region of origin included that cell.

overwinter or continued on to other areas of the Caribbean or to Mexico by using this alternate migration route [44].

It is not unusual for migratory patterns to vary among individuals and populations, and partial migration is a widely documented phenomenon within vertebrate groups, in which a portion of the population migrates, while the remainder are resident [45-48]. The classic form of non-breeding partial migration occurs when migrants and residents breed sympatrically but overwinter apart, and a separate partial migration, termed breeding partial migration, occurs when migrants and residents overwinter together but breed allopatrically [9]. Often, the migratory tendency tends to be conditionally based on asymmetries of individuals [9]. The partial migration observed in this study of monarchs is unique, as migrants and residents would not overlap geographically, if it were not for the individuals with incomplete migration that switch from a migratory to a resident strategy. Because this pattern fits neither of the established partial migration definitions [9], we refer to it as alternate migration.

We have developed two hypotheses that explain the pattern we observed. One hypothesis is that these results are due to random chance, including butterfly displacements by weather [26]. Alternatively, monarchs may employ condition-dependent alternative migration strategies. Sinceenvironmental conditions in south Florida do not favor diapause, monarchs entering this population are likely to exit diapause and begin reproducing without the need to overwinter first, regardless of the cause for

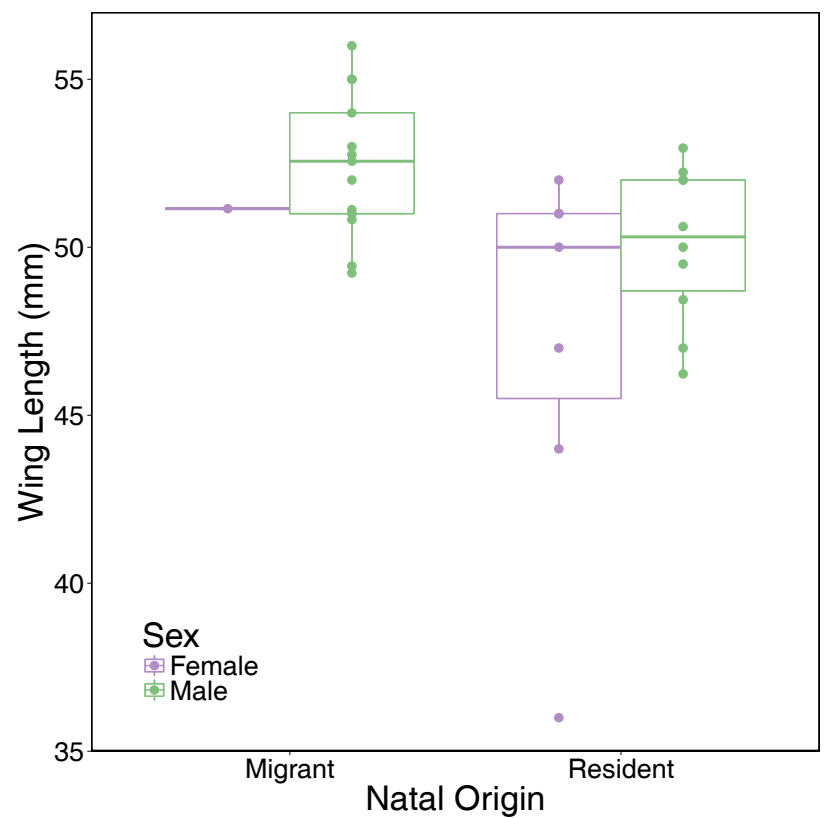

Figure 4. Wing length differences between migrant and resident monarchs collected in south Florida. Points indicate individuals. Box limits show first and third quartiles, whiskers indicate 1.5 * inter-quartile range, and horizontal bar indicates median. Only one female was classified as migrant.

settling in south Florida. Thus, this alternative migration strategy may provide a reproductive advantage for individuals whose condition makes it unlikely they would survive the winter in Mexico. Physiological triggers for condition-dependent responses have been shown to vary 
by sex for some Lepidoptera [49], which may contribute to the differing ratios of migrant males versus females that we observed.

There are two components of condition, not mutually exclusive, that might serve as triggers for selecting either a migratory or a resident life history strategy. Larval condition could determine the strategy that an adult would pursue, for example, as determined by the quality of milkweed upon which a larva feeds [17, 50, 51]. The life history strategy could also be determined by the condition of the adult and could potentially change in the midst of migration if lipid stores fall below a certain threshold, as stored lipids are critical to surviving the winter [52]. Further collection would be necessary to test these hypotheses.

Other possible explanations for recovering large numbers of migrants in south Florida include biases in our sampling protocol, or releases of farmed butterflies. Migrant butterflies were distributed across all three collection sites on both the east and west coast of south Florida, so our sampling protocol does not include obvious biases that would explain our findings.

\subsection{Monarch wing size and fitness indicators}

Wing size was larger for migratory individuals than the residents, which concurs with previously documented correlations between migratory status and distance with wing size of monarchs $[34,35,53,54]$. The size advantage migratory males hold over their resident counterparts might increase their reproductive success when switching to a resident life history strategy, as wing size has been documented an indicator of mating success [34, 55]. The size advantage may be particularly important if males were in poor condition with respect to lipid stores, as the migrant males would have the opportunity to mate immediately, rather than needing to survive until spring for mating opportunities at the overwintering colonies. However, research at the overwintering sites in Mexico suggests that mated males were smaller and had shorter wings [56]. Future studies at these sites would benefit from determining the reproductive status of all individuals.

Measuring and comparing the lipid stores in migrants entering south Florida and overwintering in Mexico could provide a more direct assessment of the condition of these butterflies and as a possible trigger of changing life history strategy. The fitness of migratory monarchs overwintering in Mexico depends not only on traversing thousands of kilometers from their summer range to the overwintering colonies, but also on accumulating sufficient lipid stores to survive the reproductively inactive winter period [52, 57]. Lipids could further be important via male investment in spermatophores, which is positively correlated with male mating success $[58,59]$. Accordingly, males with a poor body condition may experience greater mating success if they pursue an alternative strategy by migrating a shorter distance, and/or to a location where they will be able to mate more quickly.

However, there may be a tradeoff in reproductive output for migrants that settle in Florida, where they may be susceptible to the protozoan parasite Ophryocystis elektroschirrha. Of the three populations studied across North America, the non-migratory population in southern Florida had the highest parasite prevalence (over 70\%) compared to the infection rates of the eastern migratory population (8\%) and western migratory population (30\%) [60]. Parasites can be transmitted horizontally during mating or other contact as well as vertically from infected females to their offspring [61-63], and infected individuals experience decreased lifespan and reproductive success [64]. It is unlikely that any potential inbreeding in the resident population contributes to the parasite susceptibility [65]. Rather, it has been suggested that migration allows individuals to escape parasites [66-68], as infection prevalence is highest in year-round breeding monarchs where parasite spores can accumulate with the extended breeding season $[60,69]$. Thus, the Florida population may not be sustainable without the influx of breeding migrants that have lower parasite infection rates.

\subsection{Conclusions}

Much of what is known about monarch migration patterns comes from large-scale, multi-decadal mark-recapture [70] or observational [71] studies. These studies demonstrated that there are corridors of high migration, or "flyways", from the northern summer breeding areas to the southern overwintering colonies. Our results, combined with stable isotope data demonstrating trans-Appalachian flight [40], and genetic data which failed to detect population structure within North America [72], indicate that migration routes and strategies may be more complex than these broad studies indicate. It is also possible that changing climate or other unmeasured variables have altered migration patterns within the last decade. Additional studies with larger sample sizes and the use of variable and/or denser genetic markers may add further detail to the overall pattern of the major routes.

Condition-dependent alternative strategies must meet three criteria to be evolutionarily stable: (1) environmental variation must be discrete, (2) environmental cues are reliable, and (3) alternatives maximize fitness in different environments [73]. Because the environmental cues in 
south Florida do not favor continuation of diapause over the winter season, the migratory and resident alternative strategies fit the first two criteria, and our results suggest that these strategies may also meet the third criterion. Further investigation of our hypotheses on condition-dependent alternate migration strategies is needed to evaluate how well the change to a resident strategy can maximize fitness, but the results of this study lead to an important overall conclusion: monarch migration behavior is more complex than implied by the major migratory routes. Monarch migration is a unique phenomenon, and understanding sex-specific behaviors and the role of alternative life history strategies in the migration is critical to understanding the evolutionary and conservation implications of these movements. Moreover, our findings indicate that the explanation regarding discrepancies between population estimates should include an evaluation of the factors affecting alternate migration strategies to provide a more complete picture of the factors influencing monarch population size.

Acknowledgements: The authors would like to thank Elane \& Ron Nuehring of the Miami Blue Chapter of the North American Butterfly Association, who granted permission to collect monarchs in their garden (Miami site); Brittany Patterson Weber for collections of monarchs at the Naples Botanical Garden; and several anonymous reviewers who improved previous drafts of the manuscript. Support for stable isotope analysis was provided by the generous supporters of our project on PetriDish.org.

\section{References}

[1] Grönroos J., Green M., Alerstam T., To fly or not to fly depending on winds: shorebird migration in different seasonal wind regimes, Anim. Behav., 2012, 83, 1449-1457

[2] Vande Velde L., Van Dyck H., Lipid economy, flight activity and reproductive behaviour in the speckled wood butterfly: on the energetic cost of territory holding, Oikos, 2013, 122, 555-562

[3] Judge K.A., Ting J.J., Gwynne D.T., Condition dependence of male life span and calling effort in a field cricket, Evolution, 2008, 62, 868-878

[4] Leary C.J., Fox D.J., Shepard D.B., Garcia A.M., Body size, age, growth and alternative mating tactics in toads: satellite males are smaller but not younger than calling males, Anim. Behav., 2005, 70, 663-671

[5] Greenfield M.D., Shelly T.E., Alternative mating strategies in a desert grasshopper: evidence of density-dependence, Anim. Behav., 1985, 33, 1192-1210

[6] Smith M.D., Schrank H.E., Brockmann H.J., Measuring the costs of alternative reproductive tactics in horseshoe crabs, Limulus polyphemus, Anim. Behav., 2013, 85, 165-173
[7] Hews D.K., Knapp R., Moore M.C., Early exposure to androgens affects adult expression of alternative male types in tree lizards, Horm. Behav., 1994, 28, 96-115

[8] Páez D.J., Brisson-Bonenfant C., Rossignol O., Guderley H.E., Bernatchez L., Dodson J.J., Alternative developmental pathways and the propensity to migrate: a case study in the Atlantic salmon, J. Evol. Biol., 2011, 24, 245-255

[9] Chapman B.B., Brönmark C., Nilsson J.-Å., Hansson L.-A., The ecology and evolution of partial migration, Oikos, 2011, 120, 1764-1775

[10] Semmens B.X., Semmens D.J., Thogmartin W.E., Wiederholt R., López-Hoffman L., Diffendorfer J.E., et al., Quasi-extinction risk and population targets for the Eastern, migratory population of monarch butterflies (Danaus plexippus), Sci. Rep., 2016, 6, 23265

[11] Flockhart D.T.T., Pichancourt J.-B., Norris D.R., Martin T.G., Unravelling the annual cycle in a migratory animal: breedingseason habitat loss drives population declines of monarch butterflies, J. Anim. Ecol., 2015, 84, 155-165

[12] Pleasants J.M., Oberhauser K.S., Milkweed loss in agricultural fields because of herbicide use: effect on the monarch butterfly population, Insect Conserv. Divers., 2013, 6, 135-144

[13] Pleasants J., Milkweed restoration in the Midwest for monarch butterfly recovery: estimates of milkweeds lost, milkweeds remaining and milkweeds that must be added to increase the monarch population, Insect Conserv. Divers., 2016

[14] Inamine H., Ellner S.P., Springer J.P., Agrawal A.A., Linking the continental migratory cycle of the monarch butterfly to understand its population decline, Oikos, 2016, 125, 1081-1091

[15] Agrawal A.A., Inamine H., Mechanisms behind the monarch's decline, Science, 2018, 360, 1294-1296

[16] Oberhauser K., Wiederholt R., Diffendorfer J.E., Semmens D., Ries L., Thogmartin W.E., et al., A trans-national monarch butterfly population model and implications for regional conservation priorities, Ecol. Entomol., 2017, 42, 51-60

[17] Goehring L., Oberhauser K.S., Effects of photoperiod, temperature, and host plant age on induction of reproductive diapause and development time in Danaus plexippus, Ecol. Entomol., 2002, 27, 674-685

[18] Urquhart F.A., Urquhart N.R., Overwintering areas and migratory routes of the monarch butterfly (Danaus $p$. plexippus, Lepidoptera: Danaidae) in North America, with special reference to the western population, Can. Entomol., $1977,109,1583-1589$

[19] Pyle R.M., Chasing Monarchs: Migrating with the Butterflies of Passage, Houghton Mifflin Co., 1999

[20] Dockx C., Directional and stabilizing selection on wing size and shape in migrant and resident monarch butterflies, Danaus plexippus (L.), in Cuba, Biol. J. Linn. Soc., 2007, 92, 605-616

[21] Knight A., Brower L.P., The influence of Eastern North American autumnal migrant monarch butterflies (Danaus plexippus $L$.) on continuously breeding resident monarch populations in southern Florida, J. Chem. Ecol., 2009, 35, 816-823

[22] Howard E., Aschen H., Davis A.K., Citizen science observations of monarch butterfly overwintering in the southern United States, Psyche J. Entomol., 2010

[23] Zalucki M.P., Rochester W.A., Estimating the effect of climate on the distribution and abundance of Danaus plexippus: a tale of two continents, In: Hoth, J., Merino, L., Oberhauser, K.S., Pisanty, I., Price, S., Wilkinson, T. (Eds.), Proceedings 
of the North American Conference on the Monarch Butterfly, Commission for Environmental Cooperation, Montreal, Canada, 1999, 151-163

[24] Zhan S., Zhang W., Niitepõld K., Hsu J., Haeger J.F., Zalucki M.P., et al., The genetics of monarch butterfly migration and warning colouration, Nature, 2014, 514, 317-321

[25] Brower L.P., Studies on the migration of the monarch butterfly I. Breeding populations of Danaus plexippus and D. gilippus berenice in south central Florida, Ecology, 1961, 42, 76-83

[26] Urquhart F.A., Urquhart N.R., Aberrant autumnal migration of the eastern population of the monarch butterfly, Danaus plexippus plexippus (Lepidoptera: Danaidae) as it relates to the occurrence of strong westerly winds, Can. Entomol., 1979, 111, 1281-1286

[27] Knight A., A Population Study of Monarch Butterflies in NorthCentral and South Florida, Master thesis, : University of Florida, Gainesville, FL, 1998.

[28] Dockx C., Migration of the North American Monarch, Danaus plexippus, to Cuba, Dissertation, : University of Florida, Gainesville, FL, 2002.

[29] Hobson K.A., Wassenaar L.I. (Eds.), Tracking animal migration with stable isotopes, Elsevier, Amsterdam, 2008

[30] Wassenaar L.I., Hobson K.A., Natal origins of migratory monarch butterflies at wintering colonies in Mexico: New isotopic evidence, Proc. Natl. Acad. Sci., 1998, 95, 15436-15439

[31] Hobson K.A., Wassenaar L.I., Taylor O.R., Stable isotopes (סD and $\delta^{13} \mathrm{C}$ ) are geographic indicators of natal origins of monarch butterflies in eastern North America, Oecologia, 1999, 120, 397-404

[32] Bowen G.J., Statistical and geostatistical mapping of precipitation water isotope ratios, In: West, J.B., Bowen, G.J., Dawson, T.E., Tu, K.P. (Eds.), Isoscapes: Understanding Movement, Pattern, and Process on Earth through Isotope Mapping, Springer, New York, 2010, 139-160

[33] Suits N.S., Denning A.S., Berry J.A., Still C.J., Kaduk J., Miller J.B., et al., Simulation of carbon isotope discrimination of the terrestrial biosphere, Glob. Biogeochem. Cycles, 2005, 19

[34] Altizer S., Davis A.K., Populations of monarch butterflies with different migratory behaviors show divergence in wing morphology, Evolution, 2010, 64, 1018-1028

[35] Li Y., Pierce A.A., de R.J.C., Variation in forewing size linked to migratory status in monarch butterflies, Anim. Migr., 2016, 3, 27-34

[36] Hobson K., Plint T., Serrano E.G., Alvarez X.M., Ramirez I., Longstaffe $\mathrm{F}$., Within-wing isotopic $\left(\delta^{2} \mathrm{H}, \delta^{13} \mathrm{C}, \delta^{15} \mathrm{~N}\right)$ variation of monarch butterflies: implications for studies of migratory origins and diet, Anim. Migr., 2017, 4, 8-14

[37] Wassenaar L.I., Hobson K.A., Comparative equilibration and online technique for determination of non-exchangeable hydrogen of keratins for use in animal migration studies, Isotopes Environ. Health Stud., 2003, 39, 211-217

[38] Bowen G.J., Wassenaar L.I., Hobson K.A., Global application of stable hydrogen and oxygen isotopes to wildlife forensics, Oecologia, 2005, 143, 337-348

[39] Flockhart D.T.T., Wassenaar L.I., Martin T.G., Hobson K.A., Wunder M.B., Norris D.R., Tracking multi-generational colonization of the breeding grounds by monarch butterflies in eastern North America, Proc. R. Soc. B Biol. Sci., 2013, 280, 20131087
[40] Miller N.G., Wassenaar L.I., Hobson K.A., Norris D.R., Monarch butterflies cross the Appalachians from the west to recolonize the east coast of North America, Biol. Lett., 2011, 7, 43-46

[41] R Core Team, R: A language and environment for statistical computing, R Foundation for Statistical Computing, Vienna, Austria, 2016

[42] Flockhart D.T.T., Brower L.P., Ramirez M.I., Hobson K.A., Wassenaar L.I., Altizer S., et al., Regional climate on the breeding grounds predicts variation in the natal origin of monarch butterflies overwintering in Mexico over 38 years, Glob. Change Biol., 2017, 23, 2565-2576

[43] Dockx C., Brower L.P., Wassenaar L.I., Hobson K.A., Do North American monarch butterflies travel to Cuba? Stable isotope and chemical tracer techniques, Ecol. Appl., 2004, 14, 1106-1114

[44] Dockx C., Differences in phenotypic traits and migratory strategies between eastern North American monarch butterflies, Danaus plexippus (L.), Biol. J. Linn. Soc., 2012, 106, 717-736

[45] Lack D., The problem of partial migration, Br. Birds, 1943, 37, 122-130

[46] Lundberg P., The evolution of partial migration in Birds, Trends Ecol. Evol., 1988, 3, 172-175

[47] Mysterud A., Loe L.E., Zimmermann B., Bischof R., Veiberg V., Meisingset E., Partial migration in expanding red deer populations at northern latitudes - a role for density dependence?, Oikos, 2011, 120, 1817-1825

[48] Chapman B.B., Skov C., Hulthén K., Brodersen J., Nilsson P.A., Hansson L.-A., et al., Partial migration in fishes: definitions, methodologies and taxonomic distribution, J. Fish Biol., 2012, 81, 479-499

[49] Daniels J.C., Seasonal variation in the little sulphur butterfly, Eurema lisa lisa, in central Florida: how it compares to other sympatric Eurema species (Lepidoptera: Pieridae), Holarct. Lepidoptera, 1995, 2, 59-65

[50] Ladner D.T., Altizer S., Oviposition preference and larval performance of North American monarch butterflies on four Asclepias species, Entomol. Exp. Appl., 2005, 116, 9-20

[51] Atterholt A.L., Solensky M.J., Effects of larval rearing density and food availability on adult size and coloration in monarch butterflies (Lepidoptera: Nymphalidae), J. Entomol. Sci., 2010, 45, 366-377

[52] Brower L.P., Fink L.S., Walford P., Fueling the fall migration of the monarch butterfly, Integr. Comp. Biol., 2006, 46, 1123-1142

[53] Flockhart D.T.T., Fitz-gerald B., Brower L.P., Derbyshire R., Altizer S., Hobson K.A., et al., Migration distance as a selective episode for wing morphology in a migratory insect, Mov. Ecol., 2017, 5, 7

[54] Yang L.H., Ostrovsky D.M., Rogers M.C., Welker J.M., Intrapopulation variation in the natal origins and wing morphology of overwintering western monarch butterflies (Danaus plexippus), Ecography, 2015, 39, 998-1007

[55] Davis A.K., Cope N., Smith A., Solensky M.J., Wing color predicts future mating success in male monarch butterflies, Ann. Entomol. Soc. Am., 2007, 100, 339-344

[56] Van Hook T., Monarch butterfly mating ecology at a Mexican overwintering site: proximate causes of non-random mating, Dissertation, University of Florida, Gainesville, FL, 1996.

[57] Alonso-Mejía A., Rendon-Salinas E., Montesinos-Patiño E., Brower L.P., Use of lipid reserves by monarch butterflies 
overwintering in Mexico: implications for conservation, Ecol. Appl., 1997, 7, 934-947

[58] Oberhauser K.S., Male monarch butterfly spermatophore mass and mating strategies, Anim. Behav., 1988, 36, 1384-1388

[59] Oberhauser K.S., Effects of spermatophores on male and female monarch butterfly reproductive success, Behav. Ecol. Sociobiol., 1989, 25, 237-246

[60] Altizer S.M., Oberhauser K.S., Brower L.P., Associations between host migration and the prevalence of a protozoan parasite in natural populations of adult monarch butterflies, Ecol. Entomol., 2000, 25, 125-139

[61] McLaughlin R.E., Myers J., Ophryocystis elektroscirrha sp. n., a neogregarine pathogen of the monarch butterfly Danaus plexippus (L.) and the Florida queen butterfly $D$. gilippus berenice Cramer, J. Protozool., 1970, 17, 300-305

[62] Leong K.L.H., Yoshimura M.A., Kaya H.K., Williams H., Instar susceptibility of the monarch butterfly (Danaus plexippus) to the neogregarine parasite, Ophryocystis elektroscirrha, J. Invertebr. Pathol., 1997, 69, 79-83

[63] Altizer S.M., Oberhauser K.S., Geurts K.A., Transmission of the protozoan parasite, Ophryocystis elektroscirrha, in monarch butterfly populations: implications for prevalence and population-level impacts, In: Oberhauser, K.S., Solensky, M. (Eds.), The Monarch Butterfly: Biology and Conservation, Cornell University Press, Ithaca, NY, 2004, 203-218

[64] Altizer S.M., Oberhauser K.S., Effects of the protozoan parasite Ophryocystis elektroscirrha on the fitness of monarch butterflies (Danaus plexippus), J. Invertebr. Pathol., 1999, 74, 76-88

[65] Mongue A.J., Tsai M.V., Wayne M.L., Roode J.C. de, Inbreeding depression in monarch butterflies, J. Insect Conserv., 2016, 20, 477-483
[66] Altizer S., Bartel R., Han B.A., Animal migration and infectious disease risk, Science, 2011, 331, 296-302

[67] Flockhart D.T.T., Dabydeen A., Satterfield D.A., Hobson K.A., Wassenaar L.I., Norris D.R., Patterns of parasitism in monarch butterflies during the breeding season in eastern North America, Ecol. Entomol., 2018, 43, 28-36

[68] Bartel R.A., Oberhauser K.S., Roode J.C. de, Altizer S.M., Monarch butterfly migration and parasite transmission in eastern North America, Ecology, 2011, 92, 342-351

[69] Satterfield D.A., Maerz J.C., Altizer S., Loss of migratory behaviour increases infection risk for a butterfly host, Proc. $R$. Soc. Lond. B Biol. Sci., 2015, 282, 20141734

[70] Monarch Watch: Dedicated to Education, Conservation \& Research. Monarch Watch, 2016

[71] Howard E., Davis A.K., Documenting the spring movements of monarch butterflies with Journey North, a citizen science program, In: Oberhauser, K.S., Solensky, M.J. (Eds.), The Monarch Butterfly: Biology \& Conservation, Cornell University Press, Ithaca, NY, 2004, 105-114

[72] Lyons J.I., Pierce A.A., Barribeau S.M., Sternberg E.D., Mongue A.J., De Roode J.C., Lack of genetic differentiation between monarch butterflies with divergent migration destinations, Mol. Ecol., 2012, 21, 3433-3444

[73] Taborsky M., Brockmann H.J., Alternative reproductive tactics and life history phenotypes, In: Kappeler, P. (Ed.), Animal Behaviour: Evolution and Mechanisms, Springer Verlag, Berlin, 2010, 537-586

Supplemental Material: The online version of this article (DOI: 10.1515/ami-2018-0006) offers supplementary material. 